\title{
Altered expression of Armet and Mrlp51 in the oocyte, preimplantation embryo, and brain of mice following oocyte in vitro maturation but postnatal brain development and cognitive function are normal
}

\author{
Ning Wang, Liya Wang, Fang Le, Qitao Zhan, Yingming Zheng, Guolian Ding, Xijing Chen, \\ Jianzhong Sheng ${ }^{1}$, Minyue Dong, Hefeng Huang and Fan Jin \\ Department of Reproductive Endocrinology, Key Laboratory of Reproductive Genetics, Ministry of Education, and Key \\ Laboratory of Women's Reproductive Health of Zhejiang Province, Women's Hospital, Zhejiang University School of \\ Medicine, 1 Xueshi Road, Hangzhou 310006, China and ${ }^{1}$ Department of Basic Medicine, Zhejiang University School \\ of Medicine, 358 Yuhangtang Road, Hangzhou 310058, China
}

Correspondence should be addressed to F Jin; Email: jinfan@zju.edu.cn

\begin{abstract}
Despite the efforts to recapitulate the follicle environment, oocytes from in vitro maturation (IVM) have poorer developmental potential than those matured in vivo and the effects on the resultant offspring are of concern. The aim of this study was to determine altered gene expression in oocytes following IVM and to evaluate the expression of the arginine rich, mutated in early stage of tumors gene (Armet) and mitochondrial ribosomal protein L51 (Mrpl51) in embryos and brains of fetal/postnatal mice and the brain development of IVM offspring. An IVM mouse model was established while oocytes matured in vivo were used as the controls. Suppressive subtractive hybridization (SSH) and RT-PCR/western blot were used to analyze the differential expression of genes/proteins between IVM and the control group. HE staining and water maze were used to assess the histological changes in brain tissue and cognition of the offspring. The rates of fertilization, cleavage, and live birth were significantly decreased in IVM group. Thirteen genes were upregulated in IVM oocytes compared with the control, including Armet and Mrpl51. The higher level of Armet in IVM oocytes was retained in brain of newborn mice, which could be related to the upregulation of activating transcription factor 6 (Atf6) and X-box binding protein 1 (Xbp1), while Mrpl51 was expressed normally in brain of postnatal mice. No significant differences were detected in brain weight, neuronal counts, and the cognition in the offspring between the two groups. The present results suggested that IVM could affect the pregnancy outcome and the Armet and Mrpl51 gene/protein expression. The change in Armet expression lasted while the change of Mrpl51 disappeared after birth. However, the brain development of the offspring seemed to be unaffected by IVM.

Reproduction (2011) 142 401-408
\end{abstract}

\section{Introduction}

In vitro maturation (IVM) of oocytes is used to avoid ovarian hyperstimulation syndromes in patients with polycystic ovaries during IVF (Chian 2004, Suikkari \& Soderstrom-Anttila 2007). However, when oocytes are obtained from IVM, not all of them have the ability to be fertilized and develop into an embryo. The inability to sustain further development may be associated with incomplete maturation of the oocyte during folliculogenesis (Robert et al. 2001). It has become increasingly clear that genetic programs, especially the messenger RNA synthesis and storage in the oocyte, play important roles in orchestrating the multiple events required for successful folliculogenesis, fertilization, and early development (Meirelles et al. 2004). Although great efforts have been made to recreate in vitro follicular environment, the rates of blastulation and pregnancy with IVM were much lower compared with routine IVF (Lee et al. 2008). Some theoretic concerns regarding the safety of IVM have been raised (Fauser et al. 2002, Albertini et al. 2003, Krisher et al. 2007, Lee et al. 2008, Liu et al. 2010), and the potential effects of IVM on offspring are still unclear.

To identify the genes specifically expressed in IVM oocytes, we compared the mRNA profiles of mouse oocytes obtained from IVM and the control group (in vivo maturation) using suppressive subtractive hybridization (SSH). Thirteen specific differentially expressed genes in IVM oocytes were cloned, including two genes related to the neurology: the arginine rich, mutated in early stage of tumors gene (Armet) and mitochondrial ribosomal protein L51 (Mrpl51). 
Armet is an endoplasmic reticulum (ER) stressresponsive gene (Apostolou et al. 2008) required for cell protection against ER stress and is critical for specific neuronal cells to survive and is shown to play important roles in many neurodegenerative disorders (Taylor et al. 2002, Berke \& Paulson 2003, Ciechanover \& Brundin 2003, Giasson \& Lee 2003). Transcription factors activating transcription factor 6 (Atf6) and X-box binding protein 1 (Xbp1) are the promoters for Armet transcription by recognizing the sequence ACGTGG immediately downstream of $-160 \mathrm{bp}$ in the Armet promoter when the ER stress invoked (Lee et al. 2003, Mizobuchi et al. 2007).

MRPs are encoded by nuclear genes and help in protein synthesis within the mitochondrion. MRPL51 was established as a large subunit of mammalian MRPs (Gan et al. 2002) and functions in the translation of genetic messages. The redistribution of mitochondria was coordinated with oocyte maturation, and lack of redistribution of mitochondria suggested incomplete cytoplasmic maturation and lower developmental competence (Krisher et al. 2007). Mitochondrial dysfunction (including the dysfunction of MRPL51) causes more than 50 diseases ranging from neonatal fatalities to adult-onset neurodegeneration (Lopez et al. 2000, DiMauro \& Schon 2003, Lowell \& Shulman 2005, Wallace 2005).

Considering the important role of Armet and Mrpl51 in nervous-related disorders, they were further analyzed in two-cell embryos and the brain tissue of fetal and postnatal mice to investigate the possible functions of the two genes in oocyte maturation and the long-term effects of IVM. In addition, the expression of Atf6 and $X b p 1$ was analyzed to reveal the possible mechanisms for the change of Armet induced by IVM. Meanwhile, morphology and histological analysis in the brain tissue and cognitive behavioral testing were used to show brain development of the offspring.

\section{Results}

\section{Rates of fertilization, cleavage, and birth between IVM and the control group}

The rates of fertilization and cleavage were significantly lower in the IVM group than the control group (67.9 vs $85.7 \%$ and 90.9 vs $95.7 \%$ ). Similarly, the birth rate of two-cell stage transfer was significantly lower in the IVM group than the control group (15.4 vs $23.3 \%$; Fig. 1A). No significant differences were detected in weight of newborns and the number per litter between the two groups (Fig. 1B and C).

\section{SSH of oocytes}

After sequencing, 13 differential expression genes including Armet and Mrpl51 were identified as upregulated, which are listed in Table 1.
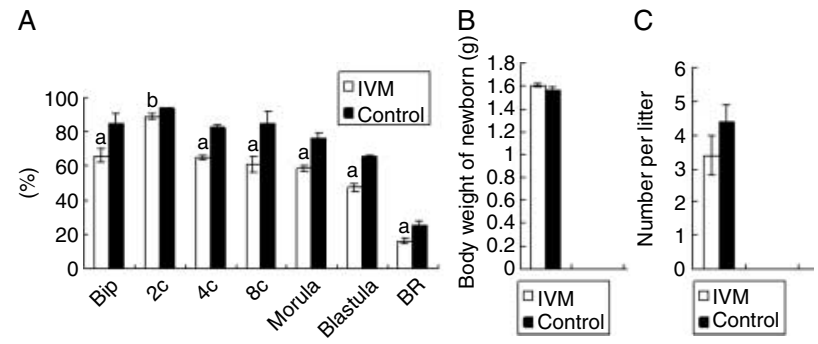

Figure 1 Effects of IVM on fertilization, preimplantation embryo development, and pregnancy outcomes. (A) The rates of fertilization and cleavage, development capability, and the birth rate (BR) of two-cell stage transfer. Bip, Bipronucleus; 2c, two-cell stage embryo; 4c, four-cell stage embryo; 8c, eight-cell stage embryo; BR, birth rate = pup number/number of two-cell embryos transferred; (B) newborn weights; (C) number per litter; a, $P<0.01$; b, $P<0.05$.

\section{The mRNA expressions in oocytes, two-cell embryos, and brains of fetal and postnatal mice}

Results of RT-PCR showed that the mRNA expression of Armet and Mrpl51 in oocytes and two-cell embryos was statistically significantly higher in IVM group than the control group (Fig. 2A).

The expression of Armet was statistically significantly higher in the brain tissue of IVM E16.5 and newborn mice, but no differences were shown in Mrpl51 expression (Fig. 2B and C).

Expression of Atf6 and Xbp1 was detected to reveal the possible pathway that might affect Armet mRNA expression. During development, the expression of Atf6/Xbp1 was coincident with the change in Armet, higher in the brain tissue of E16.5 and newborn mice in the IVM group (Fig. 2D and E).

\section{The protein expression of ARMET and MRPL51 in brains of fetal and postnatal mice}

The results of western blotting (WB) showed that ARMET was expressed in all developmental stages of mouse brain, and it was significantly higher in E16.5 and newborn stage in the IVM group than the control group; however, no significant differences between the two groups were detected in 3 and 10 weeks stages (Fig. 3A and B). MRPL51 was expressed in all development stages of mouse brains, and no significant differences between the two groups were detected (Fig. 3C and D).

\section{Brain development of the offspring}

Morphology and histology of brain tissue

The ratio of brain to body weight, the neuronal morphology, and the neuronal counts were not significantly different between the two groups (Fig. 4A-C). 
Table 1 Identification of cDNA clones found with suppressive subtractive hybridization when comparing in vitro maturation oocytes mRNAs with control group.

\begin{tabular}{lll}
\hline Gene symbol & Gene description & GenBank number \\
\hline Armet & Mus musculus arginine rich, mutated in early stage tumors & NM_029103.3 \\
Mrpl51 & Mus musculus mitochondrial ribosomal protein L51 & NM_025595.2 \\
Mitd1 & MIT, microtubule interacting and transport, domain containing 1 & NM_026913.2 \\
Socs3 & Suppressor of cytokine signaling 3 & NM_007707.2 \\
Slc1a6 & Solute carrier family 1 (high-affinity aspartate/glutamate transporter), member 6 & NM_009200.2 \\
Slc13a1 & Solute carrier family 13 (sodium/sulfate symporters), member 1 & NM_019481.1 \\
Sparcl1 & Mus musculus SPARC-like 1 (mast9 and hevin) & NM_010097.2 \\
Srgap3 & Mus musculus SLIT-ROBO Rho GTPase activating protein 3 & NM_080448.3 \\
Smarca1 & Mus musculus SWI/SNF related, matrix associated, actin-dependent regulator of & NM_053123.3 \\
LOC677366 & chromatin, subfamily a, member 1 & XM_001004722.1 \\
& Similar to sodium- and chloride-dependent glycine transporter 2 & //XM_001004719.1 \\
LOC630539 & (GlyT2) (GlyT-2) (solute carrier family 6 member 5) & XM_904071.2 \\
Zfp26 & Similar to mouse RING finger 1 /// tripartite motif-containing 59 & NM_011753.2 \\
Unknown & Zinc finger protein 26 & \\
\hline
\end{tabular}

\section{Cognitive ability of the offspring}

Cognition was assessed by performing a total of 24 trials with ten mice of each group over a period of six consecutive days with a Morris water maze (MWM) apparatus. The mean latency to find the platform during the first 6 days and the times of crossing the former platform in the probe trial did not differ significantly between the two groups (Fig. 4D).

\section{Discussion}

By using about 500 oocytes for each test, SSH was applied to compare the differences of whole genome transcription profiles between the oocytes matured through IVM and from in vivo in mice. Although it did not seem to be as sensitive as the assay with microarray in other species, the present SSH test offered much more focused information requiring relatively small sample amounts. In our research, we revealed that IVM could affect the pregnancy outcome and the expression of Armet and/or Mrpl51 in mouse oocytes, embryos, and the brain of fetal mice. Although Mrpl51 was expressed normally after birth in IVM mouse brain, the change in Armet lasted after the birth. The alteration in Armet expression in IVM was consistent with the change in Atf6/Xbp1 expression. However, no significant differences were shown in the morphology and histological analysis of the brain and cognition in the offspring between the two groups. This is the first report of the effects of IVM on Armet (and Atf6/Xbp1) and Mrpl51 expression in mouse oocytes, embryos, and the brains of fetal and postnatal mice.

Armet was described as a survival-promoting factor for embryonic midbrain dopaminergic neurons in vitro (Petrova et al. 2003) and protects neurons against cerebral ischemia, possibly by inhibiting cell necrosis/ apoptosis in cerebral cortex (Airavaara et al. 2009). Drosophila Armet-deficient flies die as embryos, showing severe degeneration of dopaminergic axons and a drastic decrease in the level of dopamine (Lindholm et al. 2008). In the brain, Armet mRNA levels could be influenced by pathological conditions, and global forebrain ischemia could increase Armet expression (Lindholm et al. 2008). In our research, the higher Armet levels were not only found in IVM oocytes and embryos but also existed in brain of fetal and newborn mice conceived from IVM. Combined with the results of lower rates of fertilization, cleavage, and birth in the IVM group, it is implied that oocyte insults induced by IVM procedure lead to the specific changes in gene expression in the brains of IVM mice in the similar condition (similar newborn weight and litter size). Reports have shown that ARMET plays important roles in diseases such as ER stress (DeGracia \& Montie 2004, Apostolou et al. 2008), type II diabetes, Parkinson's disease, and Alzheimer's disease (Lindholm et al. 2006, Ron \& Walter 2007). Although we did not find significant differences in morphology, histological analysis, and cognitive behavioral testing in the IVM offspring, the relationship between IVM and potential diseases, especially neural disorders, needs further research with larger samples of animal or human data.

ATF6 was a specialized transcription factor for ER quality control (Adachi et al. 2008). ATF6 and XBP1 play key roles in the unfolded protein response by inducing ER chaperones and ER-associated protein degradation machineries (Mizobuchi et al. 2007). Reports showed that Armet gene expression in cultured cardiac myocytes could be induced by either Atf6 or Xbp1(Adachi et al. 2008). The higher levels of Atf6 and Xbp 1 in the IVM group proved that the change in Armet might be related to Atf6/Xbp1. IVM might upregulate the expression of $A t f 6 / X b p 1$ and then lead to the increase in Armet expression.

Mrpl51 functions in the translation of genetic messages, and the redistribution of mitochondria was coordinated with oocyte maturation competence (Krisher et al. 2007). Liu et al. (2010) reported that the 

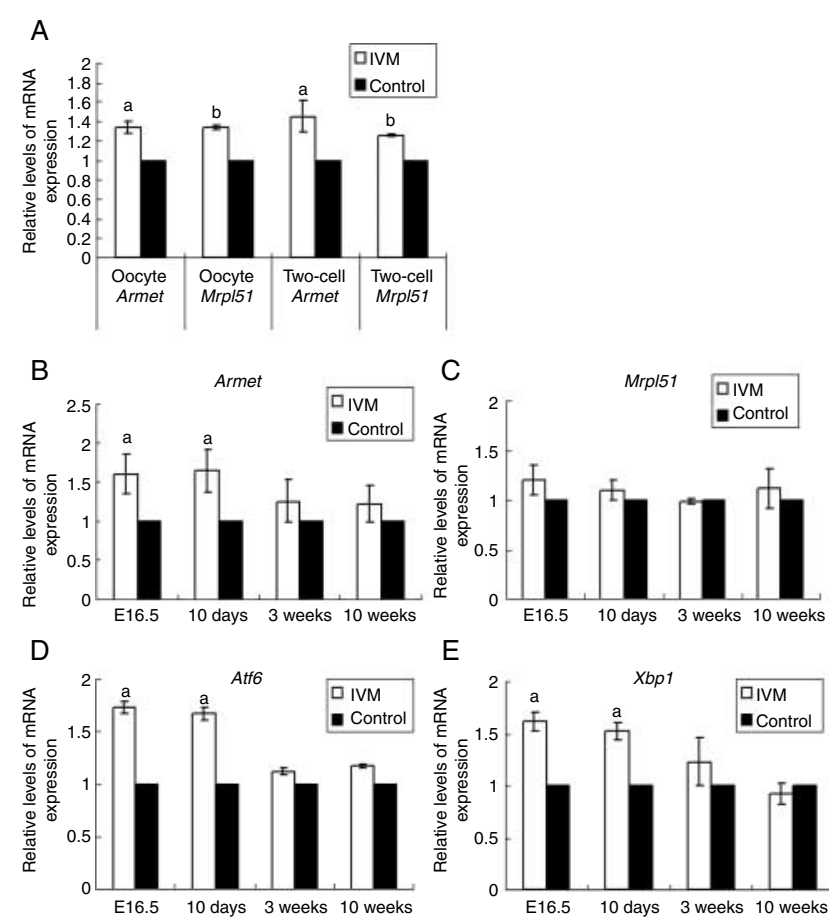

Figure 2 The mRNA expression of oocytes, two-cell embryos, and mouse brains. The comparison of mRNA expression was made between IVM and control group. Summary data show the relative expression levels in oocytes, embryos, and brains of fetal and postnatal mice after real-time PCR analysis. The relative mRNA levels represent the amount of mRNA expression normalized to Gapdh. (A) Armet and Mrpl51 mRNA expression in oocytes and two-cell embryos; (B) Armet mRNA expression in mouse brains (E16.5, 10 days, 3 weeks, and 10 weeks); (C) Mrpl51 mRNA expression in mouse brains (E16.5, 10 days, 3 weeks, and 10 weeks); (D) Atf6 mRNA expression in mouse brains (E16.5, 10 days, 3 weeks, and 10 weeks); (E) Xbp1 mRNA expression in mouse brains (E16.5, 10 days, 3 weeks, and 10 weeks). a, $P<0.01 ; b, P<0.05$.

distribution of mitochondria in human oocytes was changed after maturation, which may partially explain the reduced developmental potential of oocytes from IVM compared with the control. The increased level of Mrpl51 in the IVM group might be a way to increase the maternal reserve to ensure subsequent normal development; however, whether or how much the mitochondrial function could be compensated is unknown. Disorders of MRPs are related to mitochondrial diseases (Seyda et al. 2001). The gene abnormality can decrease the efficiency of oxidative phosphorylation and lead to the disorder of energy metabolism. In order to reveal whether the abnormal expression of Mrpl51 in IVM oocytes and embryos would be a potential risk of some mitochondrial diseases for the offspring, we detected the mRNA and protein expression during the brain development from the fetus to adulthood. No statistical differences were shown between the IVM and control groups, which indicated that the influence of IVM on Mrpl51 expression was limited to the preimplantation stage, or that embryos with abnormal Mrpl51 expression failed to go through post-implantational development.

Genes related to neuron development were found to be abnormally expressed in the IVM group; however, along with the growth and development, most abnormal expression levels disappeared in the same condition. Meanwhile, no differences were found due to IVM in postnatal brain histology and cognition compared with those of control animals, which suggests that mice born following IVM could correct some abnormal gene expression profile and develop normally, and the technique is comparatively safe if a healthy baby is delivered.

In conclusion, upregulation of the ER stress pathway as indicated by increased Armet, Xbp1, and AtfG expression following IVM may, to some degree, be beneficial for oocyte health and subsequent development by restoring protein folding and cell function leading to normal postnatal brain development as observed in the current study. However, upregulation of the ER stress pathway is not sufficient to restore cell function to in vivo levels as demonstrated by decreased fertilization rate, preimplantation embryo development, and decreased number of viable pups following transfer of embryos derived from IVM oocytes. Meanwhile, this study was performed with mice of normal fertility and does not exclude effects of the etiology of the underlying fertility within clinical populations. Additional studies are required to determine IVM effects in the patients under other more complex circumstances.

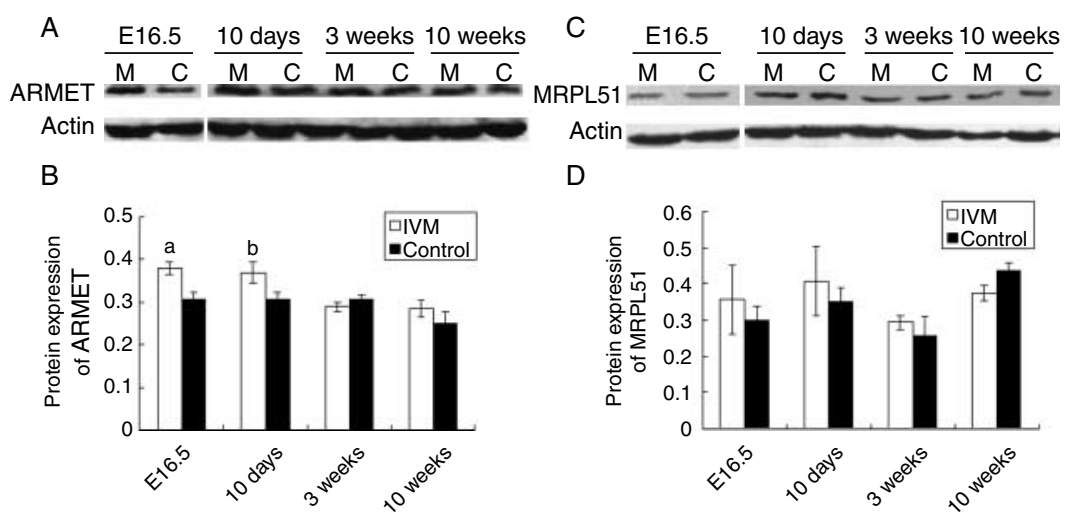

Figure 3 Protein expression in mouse brains. Bands of western blotting (WB) were captured and analyzed by Quantity One Software from three replicate experiments. Protein loads of $50 \mu \mathrm{g}$ were applied. (A) Bands of ARMET and actin from the two groups; (B) the ratio of ARMET/actin in E16.5, 10 days, 3 weeks, and 10 weeks between IVM and the control group; (C) bands of MRPL51 and actin from the two groups; (D) the ratio of MRPL51/actin in E16.5, 10 days, 3 weeks, and 10 weeks between IVM and the control group. a, $P<0.01 ; b, P<0.05$. 
A

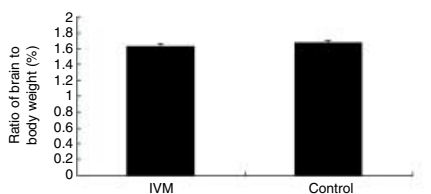

C

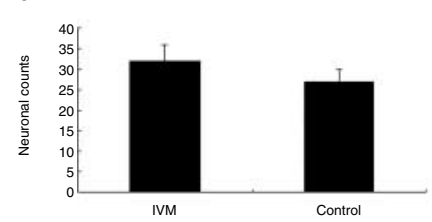

D1

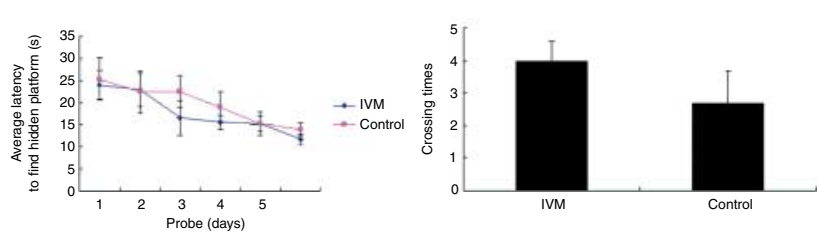

Figure 4 Brain development of the offspring. (A) The ratio of brain weight to body weight between the two groups $(P>0.05)$; (B) morphology of the neuronal cell. (B1) IVM, (B2) control; bar $=20 \mu \mathrm{m}$; (C) neuronal counts between the two groups $(P>0.05)$; (D) results from the Morris water task $(n=10)$. (D1) average latency to find the hidden platform (acquisition trials); (D2) crossing times $(P>0.05)$.

\section{Materials and Methods}

\section{Establishment of the IVM mouse model}

Experimental animals

Animal care and procedures were carried out following Institutional Guidance of the Laboratory Animal of the Animal Care of Usage Committee (ACUC) of Zhejiang University and the protocol was approved by the ACUC of Zhejiang University School of Medicine. Female C57BL/6) and ICR mice (6-7 weeks old) and male mice (8-12 weeks old) were housed in $12 \mathrm{~h}$ light: $12 \mathrm{~h}$ darkness cycle at $25 \pm 0.5{ }^{\circ} \mathrm{C}$ and $50-60 \%$ humidity. The mice were fed with a standard pellet diet and water.

\section{Collection of oocytes}

For IVM experiments, the cumulus-enclosed oocytes at germinal vesicle (GV) stage were selected from ovaries 46-48 h after injected (i.p.) with $7.5 \mathrm{IU}$ pregnant mare serum gonadotropin (PMSG; Pregnyl, Organon, Oss, The Netherlands). Oocytes were matured to metaphase II (MII) stage as described previously (Junk et al. 2003, Nishi et al. 2003). Briefly, GV stage oocytes were cultured in human tubal fluid medium (HTF; Irvine Scientific, Santa Ana, CA, USA) containing $10 \%$ serum substitute supplement (SSS, Irvine Scientific) with $0.1 \mathrm{IU} / \mathrm{ml} \mathrm{FSH} \mathrm{(Gonal} \mathrm{F,} \mathrm{Serono)} \mathrm{and} 0.5 \mathrm{IU} / \mathrm{ml}$ human chorionic gonadotropin (hCG, Pregnyl, Organon) for $16-18 \mathrm{~h}$ at $37{ }^{\circ} \mathrm{C}$ in a humidified atmosphere of $5 \% \mathrm{CO}_{2}$. For the control group, all mice received an i.p. injection of $7.5 \mathrm{IU}$
hCG 46-48 $\mathrm{h}$ after the administration of 7.5 IU PMSG. Mice were killed by cervical dislocation 12-14 h after hCG injection and the oviducts were excised and cumulus masses with oocytes matured in vivo were obtained (Ruan et al. 2006).

The collected cumulus masses from the two groups were digested with hyaluronidase $(80 \mathrm{IU} / \mathrm{ml}$, Sigma) to remove granulosa cells. The naked oocytes were either cultured in pre-equilibrated $10 \%$ SSS HTF medium at $37^{\circ} \mathrm{C}$ in humidified $5 \% \mathrm{CO}_{2}$ for fertilization or washed three times with PBS for mRNA extraction.

\section{ICSI and embryo transfer}

ICSI was performed immediately with fresh sperm after collection from epididymis using PIEZO (PrimeTech, Ibaraki, Japan) assistance on an Olympus X71 inverted microscope with Narishige micromanipulators (Narishige, Tokyo, Japan) at $37^{\circ} \mathrm{C}$ warm plate as described previously (Yoshida \& Perry 2007). Injected oocytes were cultured in $10 \%$ SSS HTF medium at $37{ }^{\circ} \mathrm{C}$ in humidified $5 \% \mathrm{CO}_{2}$ overnight. Some of the two-cell embryos were used for transfer; the others were washed three times with PBS for mRNA extraction.

Embryos at two-cell stage were transferred into the oviducts (15 per oviduct) of $0.5 \mathrm{~d}$ pseudopregnant female mice (Lacham-Kaplan et al. 2003). Some pregnant recipients were killed at E16.5 and the uteri were excised to obtain fetal mice. The rest were allowed to go to term and give birth to live offspring for analysis and subsequent breeding.

Brain tissues obtained from mice at E16.5, 10 days, 3 weeks, and 10 weeks stages of IVM and the control group were snap frozen in liquid nitrogen just after collection for half an hour and finally stored at $-80^{\circ} \mathrm{C}$ for further RNA and protein extraction.

\section{Suppressive subtractive hybridization}

RNA was extracted from 500 oocytes using Trizol reagent (Takara, Tokyo, Japan) according to the manufacturer's protocol. SMART cDNA synthesis kit (Clontech Laboratories) was used for the synthesis of double-stranded cDNA. SSH was performed with the PCR-Select cDNA Subtraction Kit (Clontech Laboratories) according to the manufacturer's instructions.

The subtracted PCR products were cloned into the PMD-19 vector (Takara). After transformation by heat shock in $200 \mu \mathrm{l}$ competent DH5a Escherichia coli cells, colonies were then isolated and grown. The insertion of each colony was amplified using PCR. After electrophoresis on the 2\% agarose gel, positive and single clones were sent to a sequencing service, and their sequences were submitted for a Blast analysis in GenBank for identification.

\section{Quantitative real-time RT-PCR}

Total RNA was extracted from oocytes (500), embryos (500), and brain tissues (about $100 \mathrm{mg}$; including several developmental stages E16.5, 10 days, 3 weeks, and 10 weeks) using Trizol reagent according to the manufacturer's protocol. Differential gene expressions were detected using the SYBR PrimeScript RT-PCR Kit (Takara). For RT, $4 \mu \mathrm{l} 5 \times$ PrimeScript 
Buffer PCR buffer, $1 \mu$ l PrimeScript RT enzyme mix I, $1 \mu$ I Oligo dT primer $(50 \mu \mathrm{M}), 1 \mu \mathrm{l}$ random 6 mers $(100 \mu \mathrm{M})$, and $10 \mu \mathrm{l}$ RNA sample for oocytes (or $1 \mathrm{ng}$ for brain tissues) were added into the $20 \mu \mathrm{l}$ reaction system. The mixture was incubated at $37^{\circ} \mathrm{C}$ for $15 \mathrm{~min}$, and the reaction was inactivated at $85^{\circ} \mathrm{C}$ for $5 \mathrm{~s}$. RT products were amplified by real-time PCR with SYBRGreen I (Takara, Foster City, CA, USA) on ABI 7900 real-time PCR system (Applied Biosystems, Tokyo, Japan) according to the manufacturer's protocol and using Gapdh as an internal control. Primers used for the experiments were designed by the Primer Express 3.0 program. Primer sequences for the following genes are as follows:

Armet: (f) TGCTGCCACCAAGATCATCAA, (r) AGGTCCACTGTGCTCAGGTCAA; Mrpl51: (f) TTGGCCTTCGTAAGGCTCACTC, (r) CGGACACAACGCTGCAATTC; Atf6: (f) AGTCCCAAGTCCAAAGCGAAGA, (r) CTGATTGGCAGGGCTCACACTA; Xbp1: (f) AGTTAAGAACACGCTTGGGAATGG, (r) CTGCTGCAGAGGTGCACATAGTC; Gapdh: (f) TGACGTGCCGCCTGGAGAAA, (r) AGTGTAGCCCAAGATGCCCTTCAG.

Real-time PCR was carried out in a $20 \mu \mathrm{l}$ reaction system containing $10 \mu \mathrm{l}$ SYBR Premix Ex Taq, $0.4 \mu \mathrm{l}$ PCR forward primer $(10 \mu \mathrm{M}), 0.4 \mu$ I PCR reverse primer $(10 \mu \mathrm{M}), 0.4 \mu \mathrm{I}$ ROX reference dye, and $2 \mu \mathrm{l}$ cDNA sample. PCR was performed with $95^{\circ} \mathrm{C}$ for $10 \mathrm{~s}$ and 40 cycles at $95^{\circ} \mathrm{C}$ for $5 \mathrm{~s}, 60^{\circ} \mathrm{C}$ for $30 \mathrm{~s}$. The mRNA levels of target genes were standardized with those of Gapdh reference gene and the average fold values were calculated. Data (three biological repeats and three technical repeats at each time point) were analyzed by the comparative threshold cycle $\left(C_{\mathrm{T}}\right)$ method and the standard formula (Schefe et al. 2006). Each reaction was performed in triplicate. We choose three pools of oocytes/embryos from 15 mice and three brains from three mice every time, and the same experiment was repeated three times.

\section{Western blotting}

The brain proteins were extracted using about $100 \mathrm{mg}$ tissues in a radioimmunoprecipitation buffer (Takara) according to the manufacturer's protocol. Protein samples were separated by SDS-PAGE (6\% gel; $50 \mu \mathrm{g}$ per lane) and then transferred to a polyvinylpyrrolidone membrane. The membrane was blocked and then incubated overnight with the primary antibody (goat polyclonal antibody, MRPL51, 1:500; Santa Cruz Biotechnology, Inc. (Paso Robles, CA, USA); goat polyclonal antibody, ARMET, 1:500; Santa Cruz Biotechnology, Inc.; rabbit anti- $\beta$-actin, 1:1000; Sigma). After washing three times with tris-buffered saline with $0.1 \%$ Tween-20, the membrane was incubated with secondary antibody (HRP-conjugated rabbit anti-goat $\operatorname{lgG}(\mathrm{H}+\mathrm{L})$ for MRPL51 and ARMET and HRP-conjugated goat anti-rabbit $\lg \mathrm{G}(\mathrm{H}+\mathrm{L}), 1: 5000$; Sigma) conjugated with HRP for $1 \mathrm{~h}$ at RT. The signal was detected with the ECL Advance WB detection reagents (Amersham). Five mice of each group were used each time, and the experiment was repeated three times. Data were analyzed by the Quantity One software (Bio-Rad).

\section{Brain development of the offspring}

In order to detect whether the changes in the gene/protein expression could affect the brain development of the postnatal mice, we chose morphology, histological analysis, and cognitive behavioral testing as the targets.

\section{Morphology and histology of brain tissue}

Ten-week-old mice were weighed, and the brains were removed from the body and weighed after the mice were killed. The ratio of organs to body weight was calculated. The brains were fixed in $4 \%$ paraformaldehyde and embedded in paraffin. Paraffin section $(5 \mathrm{~mm})$ was stained by hematoxylin and eosin (H\&E). The slides were observed under the microscope, and five to eight regions within the H\&E section of cortex were examined and scored at $400 \times$ magnification. Morphology of the brain was observed and neuronal counts in the cerebral cortex were measured (Ratai et al. 2011).

\section{Cognition of the offspring}

The MWM test was performed using a tracking system (PolyTrak; San Diego Instruments, San Diego, CA, USA) as described previously (Ecker et al. 2004, Vorhees \& Williams 2006). Spatial training occurred at 8 weeks of age over a 6-day period in a MWM using ten male mice from each group. Each mouse was given $60 \mathrm{~s}$ to find the hidden platform, and the latency to find the platform was recorded. The animals were placed in four different quadrants for four trials every day. After completing the trials, each animal performed one probe trial, in which the platform was removed from the pool. The probe trial was performed to verify the animal's understanding of the platform location and observe the strategy that the animal follows when it discovered the platform was not there. The number of times each animal crossed the former location of the platform was recorded during $30 \mathrm{~s}$. The data were analyzed by the tracking system software to evaluate the animals' learning and memory.

\section{Statistical analysis}

Data represent mean (s.D.). For comparison of the rates of fertilization, cleavage, and development capability in the preimplantation embryos and the rates of birth in the offspring, the $\chi^{2}$ test was used. The other data were analyzed by independent $t$-test for significant differences among different groups. (Statistical Package for the Social Science (SPSS) 16.0 (SPSS, Inc., Chicago, IL, USA) was used and differences were considered significant at $P$ value $<0.05$.

\section{Declaration of interest}

The authors declare that there is no conflict of interest that could be perceived as prejudicing the impartiality of the research reported.

\section{Funding}

The research was supported by the National Basic Research Program of China (2007CB948104), Natural Science Foundation Projects (8170532), and Natural Science Foundation Projects of Zhejiang (Z207021). 


\section{Acknowledgements}

The authors would like to thank the staff at the Key Laboratory of Reproductive Genetics, Ministry of Education, and Key Laboratory of Women's Reproductive Health of Zhejiang Province for assistance with the experiment.

\section{References}

Adachi Y, Yamamoto K, Okada T, Yoshida H, Harada A \& Mori K 2008 ATF6 is a transcription factor specializing in the regulation of quality control proteins in the endoplasmic reticulum. Cell Structure and Function 33 75-89. (doi:10.1247/csf.07044)

Airavaara M, Shen H, Kuo CC, Peranen J, Saarma M, Hoffer B \& Wang $Y$ 2009 Mesencephalic astrocyte-derived neurotrophic factor reduces ischemic brain injury and promotes behavioral recovery in rats. Journal of Comparative Neurology 515 116-124. (doi:10.1002/cne. 22039)

Albertini DF, Sanfins A \& Combelles CM 2003 Origins and manifestations of oocyte maturation competencies. Reproductive Biomedicine Online 6 410-415. (doi:10.1016/S1472-6483(10)62159-1)

Apostolou A, Shen Y, Liang Y, Luo J \& Fang S 2008 Armet, a UPRupregulated protein, inhibits cell proliferation and ER stress-induced cell death. Experimental Cell Research 314 2454-2467. (doi:10.1016/j. yexcr.2008.05.001)

Berke SJ \& Paulson HL 2003 Protein aggregation and the ubiquitin proteasome pathway: gaining the upper hand on neurodegeneration. Current Opinion in Genetics \& Development 13 253-261. (doi:10.1016/ S0959-437X(03)00053-4)

Chian RC 2004 In-vitro maturation of immature oocytes for infertile women with PCOS. Reproductive Biomedicine Online 8 547-552. (doi:10.1016/ S1472-6483(10)61101-7)

Ciechanover A \& Brundin P 2003 The ubiquitin proteasome system in neurodegenerative diseases: sometimes the chicken, sometimes the egg. Neuron 40 427-446. (doi:10.1016/S0896-6273(03)00606-8)

DeGracia DJ \& Montie HL 2004 Cerebral ischemia and the unfolded protein response. Journal of Neurochemistry 91 1-8. (doi:10.1111/j. 1471-4159.2004.02703.x)

DiMauro S \& Schon EA 2003 Mitochondrial respiratory-chain diseases. New England Journal of Medicine 348 2656-2668. (doi:10.1056/ NEJMra022567)

Ecker DJ, Stein P, Xu Z, Williams CJ, Kopf GS, Bilker WB, Abel T \& Schultz RM 2004 Long-term effects of culture of preimplantation mouse embryos on behavior. PNAS 101 1595-1600. (doi:10.1073/pnas. 0306846101)

Fauser BC, Bouchard P, Coelingh Bennink HJ, Collins JA, Devroey P, Evers JL \& van Steirteghem A 2002 Alternative approaches in IVF. Human Reproduction Update 8 1-9. (doi:10.1093/humupd/8.1.1)

Gan X, Kitakawa M, Yoshino K, Oshiro N, Yonezawa K \& Isono K 2002 Tag-mediated isolation of yeast mitochondrial ribosome and mass spectrometric identification of its new components. European Journal of Biochemistry/FEBS 269 5203-5214. (doi:10.1046/j.1432-1033.2002. 03226.x)

Giasson BI \& Lee VM 2003 Are ubiquitination pathways central to Parkinson's disease? Cell 114 1-8. (doi:10.1016/S0092-8674(03)00509-9)

Junk SM, Dharmarajan A \& Yovich JL 2003 FSH priming improves oocyte maturation, but priming with FSH or hCG has no effect on subsequent embryonic development in an in vitro maturation program. Theriogenology 59 1741-1749. (doi:10.1016/S0093-691X(02)01234-7)

Krisher RL, Brad AM, Herrick JR, Sparman ML \& Swain JE 2007 A comparative analysis of metabolism and viability in porcine oocytes during in vitro maturation. Animal Reproduction Science 98 72-96. (doi:10.1016/j.anireprosci.2006.10.006)

Lacham-Kaplan O, Shaw J, Sanchez-Partida LG \& Trounson A 2003 Oocyte activation after intracytoplasmic injection with sperm frozen without cryoprotectants results in live offspring from inbred and hybrid mouse strains. Biology of Reproduction 69 1683-1689. (doi:10.1095/biolreprod.103.018184)
Lee AH, Iwakoshi NN \& Glimcher LH 2003 XBP-1 regulates a subset of endoplasmic reticulum resident chaperone genes in the unfolded protein response. Molecular and Cellular Biology 23 7448-7459. (doi:10.1128/ MCB.23.21.7448-7459.2003)

Lee YS, Latham KE \& Vandevoort CA 2008 Effects of in vitro maturation on gene expression in rhesus monkey oocytes. Physiological Genomics 35 145-158. (doi:10.1152/physiolgenomics.90281. 2008)

Lindholm D, Wootz H \& Korhonen L 2006 ER stress and neurodegenerative diseases. Cell Death and Differentiation 13 385-392. (doi:10.1038/sj. cdd.4401778)

Lindholm P, Peranen J, Andressoo JO, Kalkkinen N, Kokaia Z, Lindvall O, Timmusk T \& Saarma M 2008 MANF is widely expressed in mammalian tissues and differently regulated after ischemic and epileptic insults in rodent brain. Molecular and Cellular Neurosciences 39 356-371. (doi:10.1016/j.mcn.2008.07.016)

Liu S, Li Y, Gao X, Yan JH \& Chen ZJ 2010 Changes in the distribution of mitochondria before and after in vitro maturation of human oocytes and the effect of in vitro maturation on mitochondria distribution. Fertility and Sterility 93 1550-1555. (doi:10.1016/j.fertnstert. 2009.03.050)

Lopez MF, Kristal BS, Chernokalskaya E, Lazarev A, Shestopalov AI, Bogdanova A \& Robinson M 2000 High-throughput profiling of the mitochondrial proteome using affinity fractionation and automation. Electrophoresis 21 3427-3440. (doi:10.1002/1522-2683(20001001)21: $16<3427::$ AID-ELPS3427>3.0.CO;2-L)

Lowell BB \& Shulman GI 2005 Mitochondrial dysfunction and type 2 diabetes. Science 307 384-387. (doi:10.1126/science.1104343)

Meirelles FV, Caetano AR, Watanabe YF, Ripamonte P, Carambula SF, Merighe GK \& Garcia SM 2004 Genome activation and developmental block in bovine embryos. Animal Reproduction Science 82-83 13-20. (doi:10.1016/j.anireprosci.2004.05.012)

Mizobuchi N, Hoseki J, Kubota H, Toyokuni S, Nozaki J, Naitoh M, Koizumi A \& Nagata K 2007 ARMET is a soluble ER protein induced by the unfolded protein response via ERSE-II element. Cell Structure and Function 32 41-50. (doi:10.1247/csf.07001)

Nishi Y, Takeshita T, Sato K \& Araki T 2003 Change of the mitochondrial distribution in mouse ooplasm during in vitro maturation. Journal of Nippon Medical School 70 408-415. (doi:10.1272/jnms.70. 408)

Petrova P, Raibekas A, Pevsner J, Vigo N, Anafi M, Moore MK, Peaire AE, Shridhar V, Smith DI, Kelly J et al. 2003 MANF: a new mesencephalic, astrocyte-derived neurotrophic factor with selectivity for dopaminergic neurons. Journal of Molecular Neuroscience 20 173-188. (doi:10.1385/ JMN:20:2:173)

Ratai EM, Annamalai L, Burdo T, Joo CG, Bombardier JP, Fell R, Hakimelahi R, He J, Lentz MR, Campbell J et al. 2011 Brain creatine elevation and $\mathrm{N}$-acetylaspartate reduction indicates neuronal dysfunction in the setting of enhanced glial energy metabolism in a macaque model of NeuroAIDS. Magnetic Resonance in Medicine [in press]. (doi:10.1002/mrm.22821)

Robert C, Gagne D, Bousquet D, Barnes FL \& Sirard MA 2001 Differential display and suppressive subtractive hybridization used to identify granulosa cell messenger rna associated with bovine oocyte developmental competence. Biology of Reproduction 64 1812-1820. (doi:10. 1095/biolreprod64.6.1812)

Ron D \& Walter P 2007 Signal integration in the endoplasmic reticulum unfolded protein response. Nature Reviews. Molecular Cell Biology $\mathbf{8}$ 519-529. (doi:10.1038/nrm2199)

Ruan HC, Zhu XM, Luo Q, Liu AX, Qian YL, Zhou CY, Jin F, Huang HF \& Sheng JZ 2006 Ovarian stimulation with GnRH agonist, but not GnRH antagonist, partially restores the expression of endometrial integrin beta3 and leukaemia-inhibitory factor and improves uterine receptivity in mice. Human Reproduction 21 2521-2529. (doi:10.1093/humrep/ del215)

Schefe JH, Lehmann KE, Buschmann IR, Unger T \& Funke-Kaiser H 2006 Quantitative real-time RT-PCR data analysis: current concepts and the novel "gene expression's $C_{\mathrm{T}}$ difference" formula. Journal of Molecular Medicine 84 901-910. (doi:10.1007/s00109-006-0097-6)

Seyda A, Newbold RF, Hudson TJ, Verner A, MacKay N, Winter S, Feigenbaum A, Malaney S, Gonzalez-Halphen D, Cuthbert AP et al. 
2001 A novel syndrome affecting multiple mitochondrial functions, located by microcell-mediated transfer to chromosome 2p14-2p13. American Journal of Human Genetics 68 386-396. (doi:10.1086/318196)

Suikkari AM \& Soderstrom-Anttila V 2007 In-vitro maturation of eggs: is it really useful? Best Practice \& Research. Clinical Obstetrics \& Gynaecology 21 145-155. (doi:10.1016/j.bpobgyn.2006.09.003)

Taylor JP, Hardy J \& Fischbeck KH 2002 Toxic proteins in neurodegenerative disease. Science 296 1991-1995. (doi:10.1126/science. 1067122)

Vorhees CV \& Williams MT 2006 Morris water maze: procedures for assessing spatial and related forms of learning and memory. Nature Protocols 1 848-858. (doi:10.1038/nprot.2006.116)
Wallace DC 2005 A mitochondrial paradigm of metabolic and degenerative diseases, aging, and cancer: a dawn for evolutionary medicine. Annual Review of Genetics 39 359-407. (doi:10.1146/annurev.genet.39. 110304.095751)

Yoshida N \& Perry AC 2007 Piezo-actuated mouse intracytoplasmic sperm injection (ICSI). Nature Protocols 2 296-304. (doi:10.1038/nprot.2007.7)

Received 4 May 2011

First decision 13 June 2011

Accepted 5 July 2011 